\title{
ERCP complicated by pseudoanerysm of right hepatic artery: A rare case report
}

\author{
Mohmed Imran Wagay, Gh Mohammad Wani, Naseer Ahmad Choh, Owvass Hamied Dar \\ Department of Radiodiagnosis and Imaging, Sher I Kashmir Institute of Medical Sciences, Soura, Srinagar District, J\&K State, India
}

\section{A B S T R A C T}

Endoscopic Retrograde Cholangio-Pancreatography (ERCP) has advantage of having both diagnostic and therapeutic utility and most common indication for endoscopic sphinterotomy is choledocholithiasis. Therapeutic ERCP is quite often associated with complications, most common being acute pancreatitis followed by bleeding. Most common source of bleeding is small branches of pancreaticoduodenal artery (PDA) which lie close to papilla. We report a rare case of leaking right hepatic artery pseudoanerysm following clearance of common bile duct (CBD) stones by ERCP presenting with shock and upper GI bleed.
Access this article online

Website:

http://nepjol.info/index.php/AJMS

DOI: 10.3126/ajms.v6i2.10546

Key words: ERCP, pseudoanerysm, endoscopic sphinterotomy, hepatic artery

\section{INTRODUCTION}

Hepatic artery aneurysms (HAA) are a rare but a clinically important phenomenon. A review of the literature between 1985 and 1995 showed that the HAA had surpassed splenic artery aneurysm (SAA) as the most frequently reported visceral artery aneurysm. ${ }^{1}$ however it is the true hepatic artery anerysm which constitutes major chunk of these cases. Psedoaneurysms of the hepatic artery and its branches are rare. Recognized causes include trauma or iatrogenesis following surgery, biliary procedures. Rarely anerysms can develop in transplant patients or following chronic pancreatitis. ${ }^{2}$ The major complication of hepatic artery aneurysms is rupture, usually causing massive hemobilia with an associated high mortality. Irrespective of etiology, coil embolisation is the procedure of choice.

\section{CASE REPORT}

Patient was a 55 year old male with postcholecystectemy status (open Cholecystectemy done 5 years back) and multiple CBD calculi documented on USG and MRCP. He underwent ERCP and endoscopic sphinterotomy with CBD clearance in the department of Gastroenterology of our institute. Patient initially developed severe abdominal pain followed by massive hematemesis and subsequently developed shock. Patient was given blood transfusion and put on inotropic support. Repeat endoscopy was done on next day and it revealed blood filled stomach and duodenum with blood coming from CBD. Urgent CT angiography was done in our department and we came across a large pseudoanerysm of right hepatic artery (Figure 1). CBD was filled with clots and revealed active contrast extravasation in the CBD (Figure 2). Few hepatic hematomas with subcapsular extension of bleeding were also noted (Figure 3). Moreover there was progressive increase in the contrast within small gut loops (Figure 4). The patient was operated immediately and ligation of right hepatic artery was done. However patient succumbed to refractory shock and died on the same day.

\section{DISCUSSION}

Choledocholithiasis is the commonest indication for endoscopic sphinterotomy. ${ }^{3}$ Pancreatitis is the main complication, occurring in up to $5 \%$ of sphinterotomies. ${ }^{3}$ Clinically significant hemorrhage occurred in 2.0 percent patients in a study by Freeman et al. ${ }^{3}$ The reason for the low rate of bleeding is probably because the vessels in the arterial plexus around the papilla are small. However, in $4 \%$ of autopsy specimens, the pancreaticoduodenal artery was within range of the sphincterotomy and it is probably this 


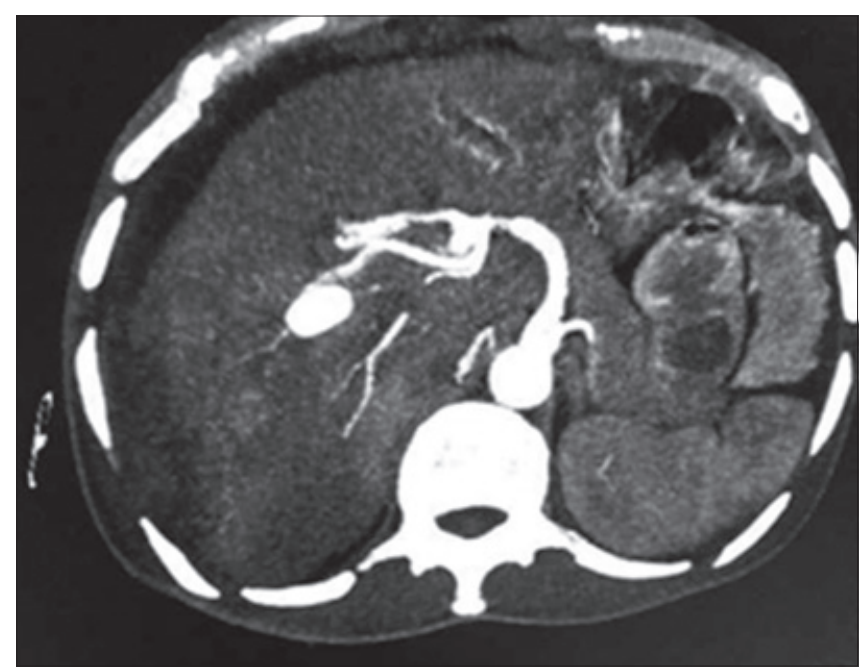

Figure 1: Axial CT MIP Image revealing a large pseudoanerysm of right hepatic artery

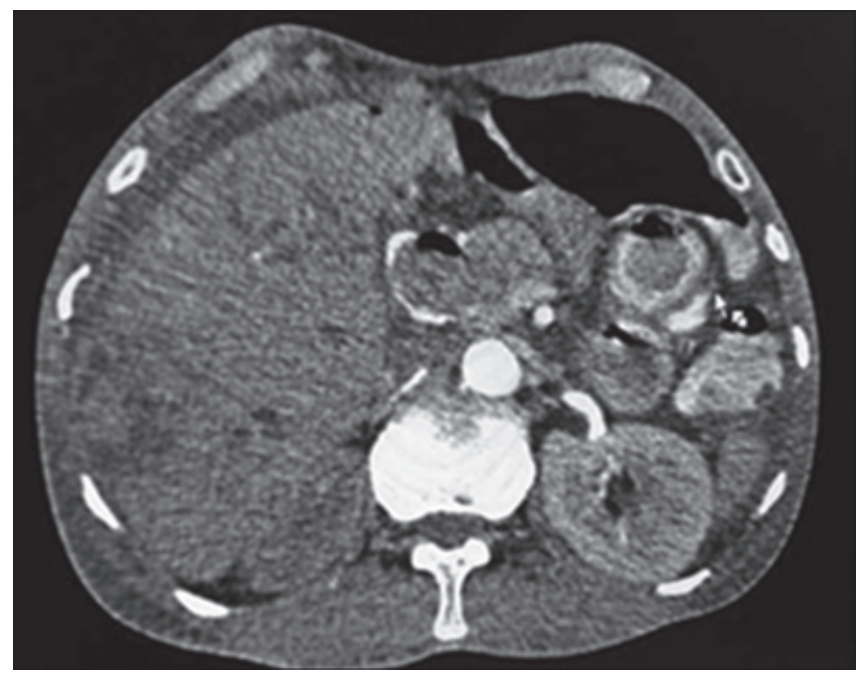

Figure 2: Axial CT revealing dilated CBD filled with blood clots with active contrast extravasation. Air is also noted within CBD (post ERCP pnemobilia)

small group of patients who are at risk of haemorrhage. ${ }^{4}$ Cholangitis may occur after diagnostic or therapeutic ERCP and is mainly due to failure to achieve adequate drainage in an obstructed system. Perforation $(<1 \%)$ is also seen in small group of patients

False aneurysms occur as a result of damage to the wall of an artery. Hepatic artery aneurysms have been frequently reported following laparoscopic cholecystectemy with more than 50 cases reported till date with more than $60 \%$ involving right hepatic artery. Hemobilia as presenting symptom has been reported in two-third of cases. ${ }^{5}$ Very few case reports of ERCP directly leading to formation of aneurysms are reported involving gastroduodenal, PDA and hepatic artery. Only two cases to our knowledge have been documented of hepatic artery aneurysm with left hepatic artery and common hepatic artery being the

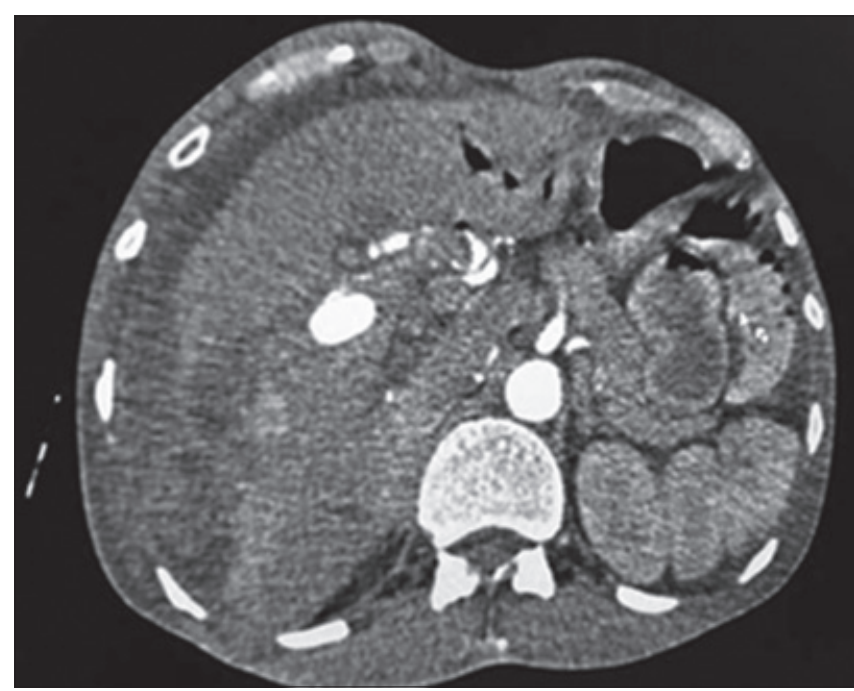

Figure 3: Axial CT showing large pseudoanerysm of right hepatic artery with parenchymal hematoma in right lobe of liver with subcapsular extension. Air is also noted in left IHBR (PostERCP)

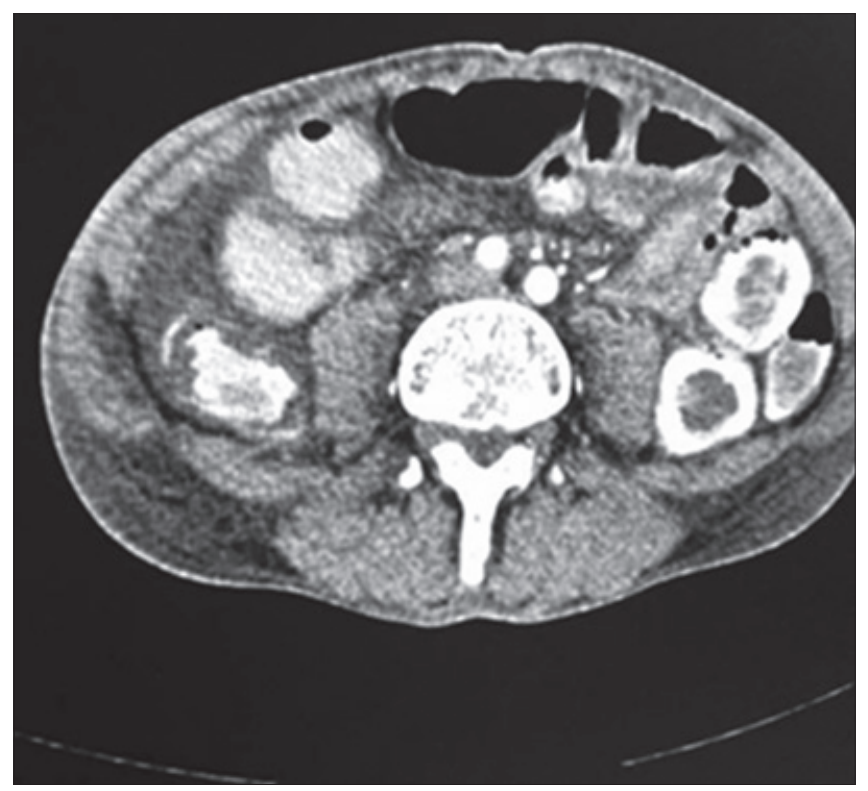

Figure 4: Axial postcontrast CT on Delayed sequences showing progressive filling of the intestines by extravasated contrast

involved artery. ${ }^{6,7}$ Our case is probably the first to report pseudoanerysm of right hepatic artery following ERCP.

\section{CONCLUSION}

This case emphasizes the fact that learning curve for therapeutic ERCP unlike diagnostic ERCP is not steep and proper expertise is needed to prevent such complications. Proper patient selection should be done and aborting the procedure in case of a difficult clearance should be considered as an option. Morever it draws attention to a rare but possible life-threatening complication of a very common procedure. High index of suspicion is necessary 
and angiography is needed to diagnose pseudoaneurysm after ERCP. Urgent management by coil embolisation or open surgery is warranted as the mortality is quite high.

\section{REFERENCES}

1. Shanley CJ, Shah NL and Messina LM: Common splanchnic artery aneurysms: splenic hepatica and celiac. Ann Vasc Surg 1996; 10:315.

2. Singh CS, Giri K, Gupta R, Aladdin M and Sawhney H. Successful management of hepatic artery pseudoaneurysm complicating chronic pancreatitis by stenting. World J Gastroenterol 2006; 12(35):5733-5734.

3. Freeman ML, Nelson DB, Sherman S, Haber GB, Herman ME,
Dorsher PJ, et al. Complications of endoscopic biliary sphincterotomy. N Engl J Med 1996; 335(13):909-918.

4. Stolte $\mathrm{M}$, Wiebner $\mathrm{V}$, Schaffner $\mathrm{O}$ and Koch $\mathrm{H}$. Vaskularisation der Papilla Vateri und Blutungsgefahr bei der. Papillotomie. Leber Magen Darm 1980; 10: 293-301.

5. Roche-Nagle G, Mac Eneaney and Harte P. Pseudo-aneurysm of the hepatic artery after laparoscopic cholecystectomy: A case report. J Min Access Surg 2006; 2:73-75.

6. Gottschalk U, Meyer DR and Steinberg J. Pseudoaneurysm of the left hepatic artery as a complication of ERCP with sphincterotomy. Z Gastroenterol 2006; 44(4):329-332. [Article in German].

7. Austin AS, Lobo DN, Hinwood D, Iftikhar SY and Norton B. Intrahepatic false aneurysm: A rare complication of ERCP. Eur J Gastroenterol Hepatol 1999; 11(10):1171-1173.

\footnotetext{
Authors Contribution:

All the authors have contributed in the conception and design of the case report. MIW - Did most of the drafting; NAC - Was instrumental in supervising the work

Source of Support: Nil, Conflict of Interest: None declared.
} 